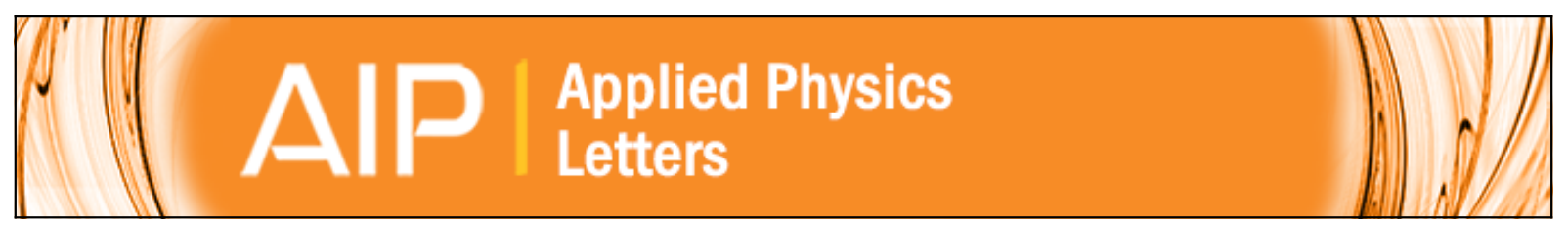

\title{
Transparent p-type SnO nanowires with unprecedented hole mobility among oxide
} semiconductors

J. A. Caraveo-Frescas and H. N. Alshareef

Citation: Applied Physics Letters 103, 222103 (2013); doi: 10.1063/1.4833541

View online: http://dx.doi.org/10.1063/1.4833541

View Table of Contents: http://scitation.aip.org/content/aip/journal/apl/103/22?ver=pdfcov

Published by the AIP Publishing

\section{Articles you may be interested in}

Influence of in-plane and bridging oxygen vacancies of $\mathrm{SnO} 2$ nanostructures on $\mathrm{CH} 4$ sensing at low operating temperatures

Appl. Phys. Lett. 105, 243102 (2014); 10.1063/1.4904457

Enhancement of p-type mobility in tin monoxide by native defects

Appl. Phys. Lett. 102, 212105 (2013); 10.1063/1.4808382

Ambipolar inverters using $\mathrm{SnO}$ thin-film transistors with balanced electron and hole mobilities

Appl. Phys. Lett. 100, 263502 (2012); 10.1063/1.4731271

Vertical p-type high-mobility heterojunction metal-oxide-semiconductor field-effect transistors

Appl. Phys. Lett. 78, 3334 (2001); 10.1063/1.1375004

A new transparent conducting oxide in the Ga 2 O 3 -In 2 O 3 -SnO 2 system

Appl. Phys. Lett. 70, 1706 (1997); 10.1063/1.118676

You don't

still use this

cell phone

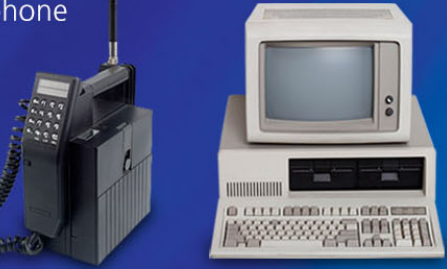

Why are you still using an AFM designed in the 80 's?
It is time to upgrade your AFM

Minimum \$20,000 trade-in discount for purchases before August 31st

Asylum Research is today's technology leader in AFM 


\title{
Transparent p-type SnO nanowires with unprecedented hole mobility among oxide semiconductors
}

\author{
J. A. Caraveo-Frescas and H. N. Alshareef ${ }^{a)}$ \\ Materials Science and Engineering, King Abdullah University of Science and Technology (KAUST), \\ Thuwal 23955-6900, Saudi Arabia
}

(Received 17 September 2013; accepted 5 November 2013; published online 25 November 2013)

p-type tin monoxide $(\mathrm{SnO})$ nanowire field-effect transistors with stable enhancement mode behavior and record performance are demonstrated at $160^{\circ} \mathrm{C}$. The nanowire transistors exhibit the highest field-effect hole mobility $\left(10.83 \mathrm{~cm}^{2} \mathrm{~V}^{-1} \mathrm{~s}^{-1}\right)$ of any p-type oxide semiconductor processed at similar temperature. Compared to thin film transistors, the $\mathrm{SnO}$ nanowire transistors exhibit five times higher mobility and one order of magnitude lower subthreshold swing. The SnO nanowire transistors show three times lower threshold voltages $(-1 \mathrm{~V})$ than the best reported $\mathrm{SnO}$ thin film transistors and fifteen times smaller than p-type $\mathrm{Cu}_{2} \mathrm{O}$ nanowire transistors. Gate dielectric and process temperature are critical to achieving such performance. C) 2013 AIP Publishing LLC. [http://dx.doi.org/10.1063/1.4833541]

Among field-effect transistors (FET), thin-film transistors (TFTs), which employ a thin film layer of a semiconducting material as the active layer, have been used for decades as a crucial component in commercial displays. ${ }^{1-4}$ Polycrystalline silicon (poly-Si) and amorphous silicon (a-Si) are widely used materials to fabricate the switching/driving TFTs for active matrix organic light emitting diode displays (AMOLED) and liquid-crystal displays (LCD), respectively. ${ }^{1,2,5}$ Nevertheless, there are intrinsic properties like their lack of transparency, rigidity, low mobility $\left(\sim 1 \mathrm{~cm}^{2} \mathrm{~V}^{-1} \mathrm{~s}^{-1}\right.$ for a-Si), or high processing temperature (poly-Si) that rules them out as alternatives for future display technologies, especially for the emerging transparent and flexible electronics. ${ }^{6,7}$ Great efforts have been exerted recently in transparent transistor research to find semiconducting materials that can replace a-Si in backplane TFTs. With transparent TFTs being the fundamental building blocks of potential transparent electronics, ${ }^{8,9}$ the suitable candidate(s) must have good optical transparency $(>90 \%$ in the visible range), high material stability, excellent device performance (high carrier mobility, high on-to-off current ratio, moderate carrier density, low threshold voltage, low sub-threshold slope), and compatibility with existing TFT fabrication technologies.

Semiconducting metal oxides stand out as the most promising candidates for future display technologies and emerging transparent electronics owing to their wide optical band gap $\left(\mathrm{E}_{\mathrm{g}}\right)$, chemical and mechanical stability, low temperature processing, and excellent device performance. Fully transparent and flexible TFTs with excellent device performance have been reported for different metal oxide semiconducting films. ${ }^{7,8,10-12}$ Furthermore, nanowire (NW) field-effect transistors based on n-type oxides such as $\mathrm{ZnO}, \mathrm{SnO}_{2}, \mathrm{In}_{2} \mathrm{O}_{3}$, or other binary and ternary oxides have been also demonstrated to show even higher field-effect mobility $\left(\mu_{F E}\right)$ to that of poly-Si $\left(150 \mathrm{~cm}^{2} \mathrm{~V}^{-1} \mathrm{~s}^{-1}\right)^{5,9,13-16}$ preserving the high optical transparency and material stability. The high mobility values reported for nanowire field effect transistors of different

\footnotetext{
${ }^{\text {a) }}$ Author to whom correspondence should be addressed. Electronic mail: husam.alshareef@kaust.edu.sa
}

materials have been attributed to confinement-induced effects. Even though the exact mechanisms that produce higher mobility in nanowire FETs are not completely clear, Trivedi et al. have shown how increased quantum confinement results in high mobility p-Si nanobelts and nanowire transistors. ${ }^{17}$ They have attributed their higher mobility values to a lower hole effective mass dispersion as the channel shrinks in dimension, i.e., holes with closer values of effective mass form the channel. $\mathrm{Ju}$ et al. have also suggested that a reduction in low-angle carrier scattering by the use of quasi-one dimensional structures might be an important mechanism for mobility enhancement. $^{5}$

Among the promising p-type candidates are cuprous oxide $\left(\mathrm{Cu}_{2} \mathrm{O}\right)$ and stannous oxide $(\mathrm{SnO})$, which have been demonstrated as p-type active channel materials in TFTs fabricated by several methods ${ }^{18-26}$ with the physical vapor deposited films exhibiting the best performance. ${ }^{19}$ The PbO-type layered structure tin monoxide is now well known to be a transparent p-type semiconductor ${ }^{27}$ with an indirect $\mathrm{E}_{\mathrm{g}} \sim 2.7$ to $2.9 \mathrm{eV}^{25,26,28}$ Its intrinsic p-type character originates from the $\mathrm{Sn}^{2+}$ vacancy and with relatively high hole mobility attributed to the hybridized $\mathrm{Sn} 5 s$ and O $2 p$ orbitals near the valence band maxima. ${ }^{27,28}$ The best reported mobility for TFTs fabricated with pure $\mathrm{SnO}$ is $1.3 \mathrm{~cm}^{2} \mathrm{~V}^{-1} \mathrm{~s}^{-1},{ }^{25}$ but it has recently been demonstrated that excess $\mathrm{Sn}$ metal in the $\mathrm{SnO}$ films can increase the mobility to above $6.0 \mathrm{~cm}^{2} \mathrm{~V}^{-1} \mathrm{~s}^{-1} .29$

Liao et al. have demonstrated p-type behavior in $\mathrm{CuO}$ and poly crystalline $\mathrm{Cu}_{2} \mathrm{O}$ single NW-FETs grown by thermal oxidation of copper foils at $500{ }^{\circ} \mathrm{C}$ (for $\mathrm{CuO}$ ) ${ }^{30}$ and further reduction in hydrogen gas for $\mathrm{Cu}_{2} \mathrm{O}$ conversion. ${ }^{31}$ Their devices exhibited field-effect mobility around 5 and $95 \mathrm{~cm}^{2} \mathrm{~V}^{-1} \mathrm{~s}^{-1}$, respectively. Despite the impressive $\mu_{F E}$ of polycrystalline $\mathrm{Cu}_{2} \mathrm{O}$ NW-FET, its high threshold voltage $\left(V_{T}\right) \sim 15 \mathrm{~V}$, low $\mathrm{E}_{\mathrm{g}}=2.17 \mathrm{eV}$, and high processing temperature make it less attractive for future applications. In contrast, the fabrication of field-effect functional devices using $\mathrm{SnO}$ nanoscale structures has not been yet demonstrated even though synthesis of $\mathrm{SnO}$ structures like nanosheets, ${ }^{32}$ nanobelts, ${ }^{33}$ and nano-rectangle strips ${ }^{34}$ have been reported. 
Here we demonstrate the fabrication of transparent $\mathrm{SnO}$ nanowire field-effect transistors with stable and well-behaved enhancement-mode p-type behavior, and a maximum linear $\mu_{F E}=10.83 \mathrm{~cm}^{2} \mathrm{~V}^{-1} \mathrm{~s}^{-1}, V_{T} \sim-1 \mathrm{~V}, \mathrm{I}_{\mathrm{ON}} / \mathrm{I}_{\mathrm{OFF}}$ ratio $>10^{3}$ at a record low temperature for active channel crystallization of $160^{\circ} \mathrm{C}$. The single NW back-gate FET structure is depicted in Figure 1(a). Indium tin oxide (ITO)-coated glass is used as transparent substrate while the $150 \mathrm{~nm}$ thick ITO layer is used as a global gate. Atomic layer deposition (ALD)-derived high-k (220 nm) $\mathrm{HfO}_{2}$ and ATO (a stacked multilayer of $\mathrm{Al}_{2} \mathrm{O}_{3}$ and $\mathrm{TiO}_{2}$ ) are used as gate dielectrics. Electron beam lithography (EBL)-patterned $\mathrm{SnO} N W$ (from a $15 \mathrm{~nm}$ thick thin film) are used as a p-type semiconducting active, and the stack is completed by $8 \mathrm{~nm} \mathrm{Ti} / 80 \mathrm{~nm}$ Au source and drain (S\&D) electrodes. $\mathrm{SnO}$ films were deposited from a 2 in. metal Tin
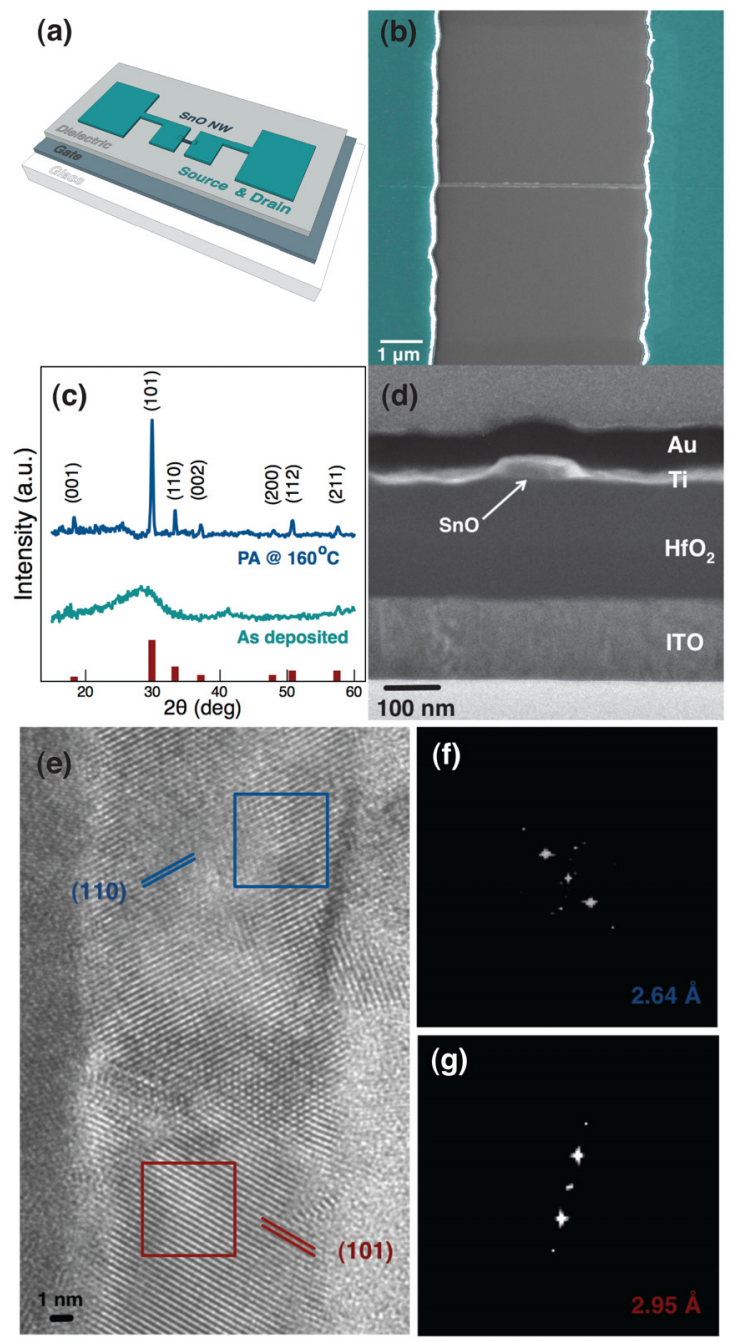

FIG. 1. (a) Conceptual design of the fabricated devices (150 nm ITO gate electrode $/ 220 \mathrm{~nm} \mathrm{HfO}_{2} / \mathrm{ATO}$ gate dielectric/EBL-patterned $\mathrm{SnO}$ nanowire channel $/ 8 \mathrm{~nm} \mathrm{Ti}, 80 \mathrm{~nm}$ Au source and drain electrodes). (b) Top view scanning electron microscopy image of fabricated device with channel length of $5 \mu \mathrm{m}$ and channel width defined by the nanowire planar width of $100 \mathrm{~nm}$; (c) $\mathrm{x}$-ray diffraction patterns of amorphous as-deposited $\mathrm{SnO}$ films and crystalline SnO films after annealing in air at $160^{\circ} \mathrm{C}$. The diffraction pattern of tetragonal SnO (JCPDS Card No. 06-0395) is shown by the red bars; (d) cross-sectional TEM image of the stack, showing the rectangular cross-sectional area of a $100 \mathrm{~nm}$ wide EBL-patterned structure; (e) HRTEM image of the SnO nanowire, viewed vertically. FFT analysis of the grains observed in the HRTEM image showing the interplanar spacing of the $(\mathrm{g})$ (110) and (f) (101) lattices of tetragonal phase SnO. target (99.99\% purity) at an oxygen partial pressure $\left(P_{O 2}\right)$ of $3.12 \times 10^{-2} \mathrm{~Pa}$ in an mixture of oxygen and argon gasses and a DC constant power of $30 \mathrm{~W}$ achieving a deposition rate of $0.8 \AA \mathrm{s}^{-1}$. The single post-annealing treatment $\left(150^{\circ} \mathrm{C}\right.$, $160^{\circ} \mathrm{C}, 170^{\circ} \mathrm{C}$ ) was performed after source and drain fabrication, in a tube furnace in air, in order to crystallize the $\mathrm{SnO}$ NWs as well as to improve the S\&D contact to $\mathrm{SnO}$.

Top view scanning electron microscopy (SEM) image of a NW-FET is shown in Figure 1(b) of a device with an effective channel length (L) of $5 \mu \mathrm{m}$ and channel width (W) defined by the planar NW width of $100 \mathrm{~nm}$. SEM images of the $200 \mathrm{~nm}$ and $500 \mathrm{~nm}$ devices are shown in Figure S1 of the supplementary material. ${ }^{35}$ The as-deposited films are amorphous, but do crystalize after a post-annealing treatment in air, in a tube furnace at temperatures as low as $160^{\circ} \mathrm{C}$. Figure $1(\mathrm{c})$ shows X-ray diffraction (XRD) patterns of as-deposited amorphous and crystallized $\mathrm{SnO}$ films showing the presence of single-phase tetragonal $\mathrm{SnO}$. The optimized tin monoxide layer is polycrystalline with an extracted crystallite size of $10-15 \mathrm{~nm}$ as confirmed by transmission electron microscopy (TEM) analysis. The SnO films themselves are transparent with an average optical transmission of $92 \%$ in the visible region of the electromagnetic spectrum $(400 \mathrm{~nm}-700 \mathrm{~nm})$, as shown in Figure S2 of the supplementary material. ${ }^{35}$ Figure 1(d) shows a cross-sectional TEM image of the stack, showing the rectangular cross-sectional area of a $100 \mathrm{~nm}$ wide EBL-patterned structure. Figure 1(e) corresponds to a highresolution TEM (HRTEM) image showing the polycrystalline nature of the nanowire. Figures $1(\mathrm{f})$ and $1(\mathrm{~g})$ show the fast Fourier transformation (FFT) analysis of the $\mathrm{SnO}$ grains observed in the HRTEM image showing the interplanar distance of $2.64 \AA$ and $2.95 \AA$, consistent with the (110) and (101) lattices of the tetragonal $\mathrm{SnO}$ phase.

Figure 2 shows the characteristic transistor curves for the best performing devices, which correspond to FETs fabricated using $\mathrm{HfO}_{2}$ as the gate dielectric and post-annealed at $160{ }^{\circ} \mathrm{C}$. Figures 2(a)-2(c) show the output characteristics of the $100 \mathrm{~nm}, 200 \mathrm{~nm}$, and $500 \mathrm{~nm}$ NW-FET, respectively. No current crowding at low drain-source voltage $\left(V_{D S}\right)$ is observed, showing Ohmic contact with the Ti/Au source and drain contacts. The well-behaved output curves exhibit a clear pinch-off and current saturation for all the FETs when operating in the negative $V_{D S}$ region. p-channel operation is confirmed by the transfer characteristics shown in Figure 2(d) since drain-source current $\left(I_{D S}\right)$ increased in all the tested devices when a negative gate-source voltage $\left(V_{G S}\right)$ was applied at a fixed $V_{D S}=-1 \mathrm{~V}$. Multiple dual-sweep $I_{D S^{-}} V_{G S}$ were obtained for several devices for each channel geometry and all curves show comparable behavior, with consistent on-off current ratio $\left(\mathrm{I}_{\mathrm{ON}} / \mathrm{I}_{\mathrm{OFF}}\right)$, sub-threshold swing $(S S)$, linear-region field-effect mobility $\left(\mu_{F E}\right)$, and threshold voltage $\left(V_{T}\right)$ values.

Multiple dual-sweep characterization was performed following the recommendations by Wager, ${ }^{36}$ and it was found that all the measured devices exhibit non-equilibrium, steady state behavior: dual-sweep $\log \left(I_{D S}\right)-V_{G S}$ transfer characteristics show hysteresis and retraceable positive-going and negative-going behavior after multiple scans. $I_{D S}$ increased for all FETs when a negative $V_{G S}$ was applied, exhibiting enhancement-mode operation $\left(I_{D S} \approx 0\right.$ at $\left.V_{G S}=0\right)$ as shown in 

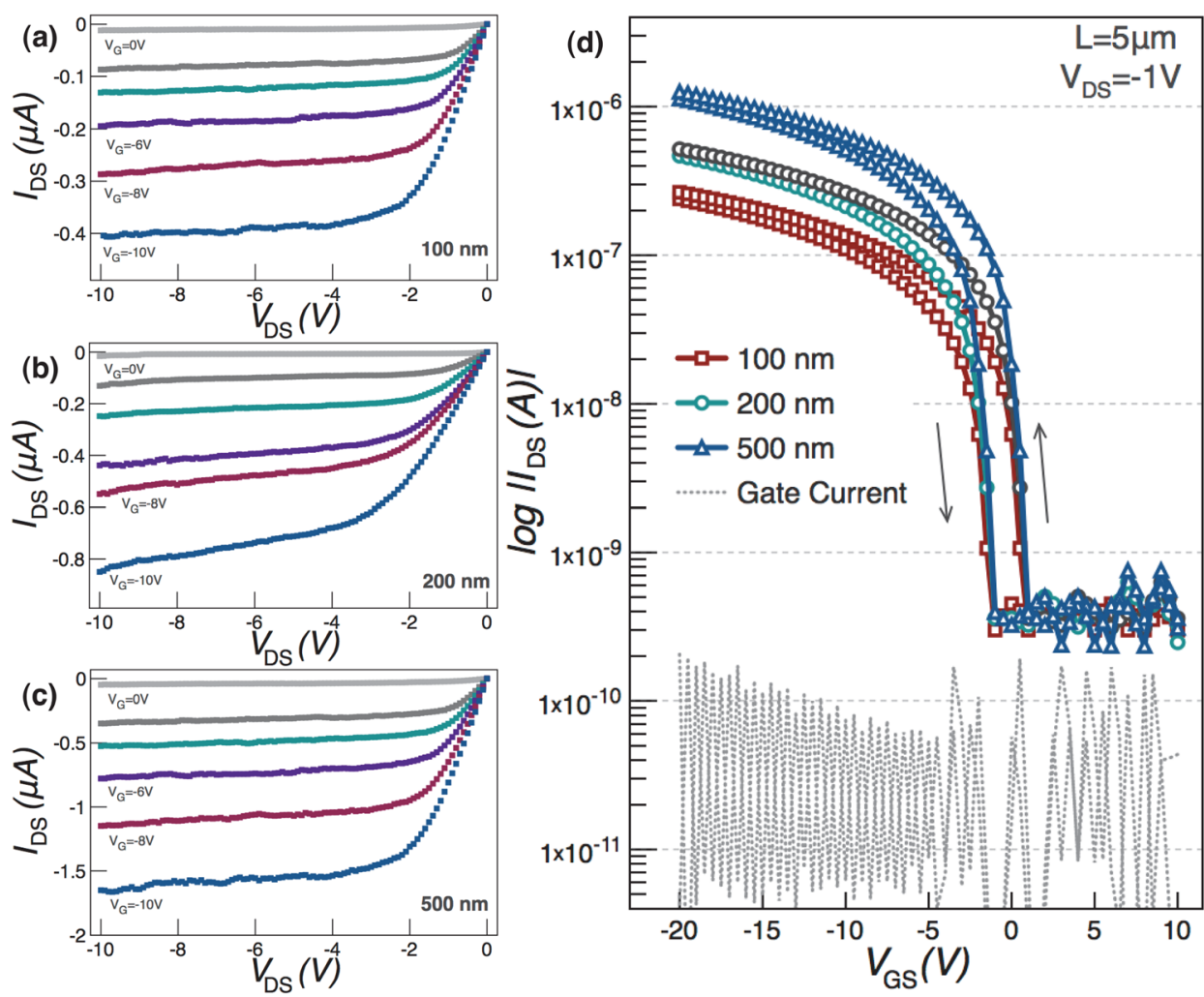

FIG. 2. Output characteristics of (a) $100 \mathrm{~nm}$, (b) $200 \mathrm{~nm}$, and (c) $500 \mathrm{~nm}$ nanowire transistors (NW-FETs), respectively. (d) Transfer characteristics of NW-FETs annealed at $160^{\circ} \mathrm{C}$ as a function of nanowire width when using $\mathrm{HfO}_{2}$ as the gate dielectric. the output characteristics of Figure 2. The off-current is $<4 \times 10^{-10}$ A for all devices while the gate leakage is $<3 \times 10^{-10}$ A reflecting the good insulating properties of the $\mathrm{HfO}_{2}$ gate dielectric. A maximum $\mu_{F E}$ of $10.83 \mathrm{~cm}^{2} \mathrm{~V}^{-1} \mathrm{~s}^{-1}$, $10.58 \mathrm{~cm}^{2} \mathrm{~V}^{-1} \mathrm{~s}^{-1}$, and $10.30 \mathrm{~cm}^{2} \mathrm{~V}^{-1} \mathrm{~s}^{-1}$ for the $100 \mathrm{~nm}$, $200 \mathrm{~nm}$, and $500 \mathrm{~nm}$ devices, respectively, with $V_{T} \sim-1 \mathrm{~V}$, $S S \approx 0.74 \mathrm{Vdec}^{-1}$, and effective hysteresis density of $N_{H Y S} \approx 7.5 \times 10^{11} \mathrm{~cm}^{-2}$ was achieved for FETs annealed at $160{ }^{\circ} \mathrm{C}$ as extracted from the transfer characteristics displayed in Figure 2(d).

The single phase SnO TFTs deposited at $P=1.8$ mTorr and $13 \% \mathrm{O}_{\mathrm{PP}}$ showed more inferior performance compared to the nanowire FET ( $\mu_{F E}$ of 1.87 vs $10.83 \mathrm{~cm}^{2} \mathrm{~V}^{-1} \mathrm{~s}^{-1}$ ), clearly demonstrating the effectiveness of nanoscaling. Table I shows the important device parameters comparing the NW FET and TFT devices fabricated with $15 \mathrm{~nm}$ thick of the same single-phase $\mathrm{SnO}$ film and same gate (ITO) and gate dielectric $\left(\mathrm{HfO}_{2}\right)$ materials. It is clear from the data in Table I that the 1-D structure (nanowire) results in substantially improved device performance. The NW-FET has 5 times higher mobility, three time smaller threshold voltage, which is also closer to zero $(-3.66 \mathrm{~V}$ for TFT to around $-1 \mathrm{~V}$ for NW-FET), lower $\mathrm{I}_{\mathrm{OFF}}$, and lower density of interfacial trap states $\left(D_{i t}\right)$ extracted from the SS. Furthermore, the NW devices show enhancement-mode operation in contrast to depletion-mode behavior of TFTs. It is important to highlight that the SS for the nanowire FET is one order of magnitude lower than the thin film device $\left(7.65 \mathrm{Vdec}^{-1}\right.$ for the TFT and $0.70 \mathrm{Vdec}^{-1}$ for the NW-FET), which gives a clear indication of the dramatic reduction in the density of interfacial trap states for nanoscale channel dimensions. The reduction in the $\mathrm{I}_{\mathrm{OFF}}$ when compared to the TFTs indicates the reduction of the surface defects (e.g., additional oxygen), which is advantageous to maximize device performance.
Our optimized post annealing temperature for the best TFT performance is $180^{\circ} \mathrm{C}$, but for the NW-FET, the best performance is observed at $160{ }^{\circ} \mathrm{C}$. This small temperature difference is crucial to avoid additional oxygen incorporation into the film, and hence we get a better mobility. TFTs annealed at $160{ }^{\circ} \mathrm{C}$ show very poor performance, most likely attributed to the incomplete crystallization of the $\mathrm{SnO}$ channel. The higher annealing temperature of TFTs allows additional oxygen to go into the exposed $\mathrm{SnO}$ surface contributing to an oxygen-rich surface and hence a higher off current. The smaller dimensions of the $\mathrm{SnO}$ nanowires allow their complete crystallization at lower temperature, which in turn reduces the likelihood of an oxygen-rich surface formation. The transfer characteristics of TFT and the $500 \mathrm{~nm}$ NW-FET are depicted in Fig. S3 of the supplementary material. ${ }^{35}$ In order to rule out narrow and short channel effects in the nanowire FETs, at least 10 devices of each NW width were tested showing consistent results.

The important FETs parameters are summarized in Figure 3 as a function of NW width and post-annealing

TABLE I. Performance comparison of NW-FET and TFT devices fabricated using the same single-phase $\mathrm{SnO}$ material.

\begin{tabular}{lccccc}
\hline \hline & \multicolumn{3}{c}{$\mathrm{NW}$ FET } & & TFT \\
\cline { 2 - 4 } \cline { 5 - 6 } & $100 \mathrm{~nm}$ & $200 \mathrm{~nm}$ & $500 \mathrm{~nm}$ & & $\mathrm{~W} / \mathrm{L}=50 \times 50 \mu \mathrm{m}$ \\
\hline$\mu_{F E}\left(\mathrm{~cm}^{2} \mathrm{~V}^{-1} \mathrm{~s}^{-1}\right)$ & 10.83 & 10.58 & 10.30 & & 1.87 \\
$V_{T}(\mathrm{~V})$ & -1.06 & -1.08 & -1.20 & -3.66 \\
$\mathrm{I}_{\mathrm{OFF}}(\mathrm{A})$ & $4 \times 10^{-10}$ & $4 \times 10^{-10}$ & $4 \times 10^{-10}$ & $1 \times 10^{-9}$ \\
$\Delta V_{O N}(\mathrm{~V})$ & 1.99 & 2.07 & 2.03 & 3.61 \\
$S S\left(\mathrm{Vdec}^{-1}\right)$ & 0.76 & 0.69 & 0.60 & 7.65 \\
$D_{i t}\left(\mathrm{eV}^{-1} \mathrm{~cm}^{-2}\right)$ & $4.45 \times 10^{12}$ & $4.00 \times 10^{12}$ & $3.43 \times 10^{12}$ & $4.82 \times 10^{13}$ \\
$N_{H Y S}\left(\mathrm{~cm}^{-2}\right)$ & $7.42 \times 10^{11}$ & $7.72 \times 10^{11}$ & $7.57 \times 10^{11}$ & $1.35 \times 10^{12}$ \\
\hline \hline & & & & \\
\hline
\end{tabular}


(a)
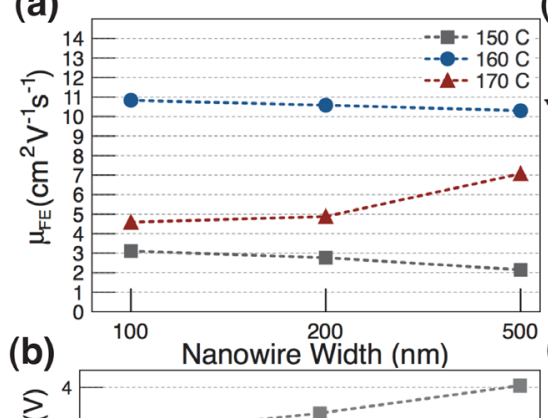

(c)

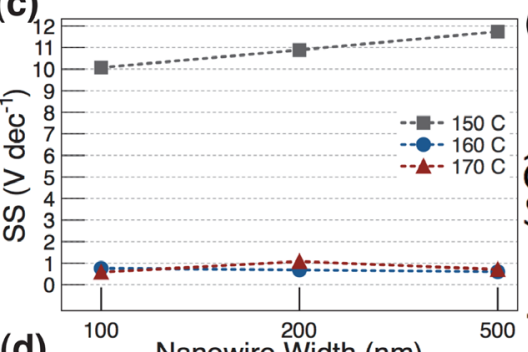

(d)
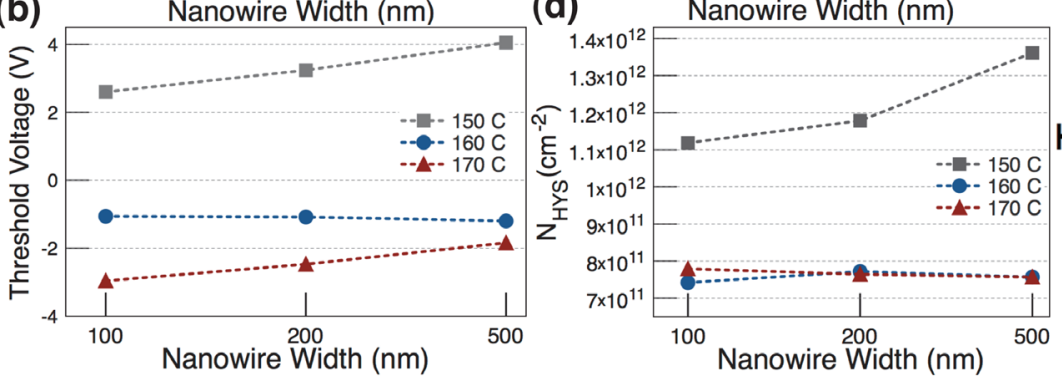

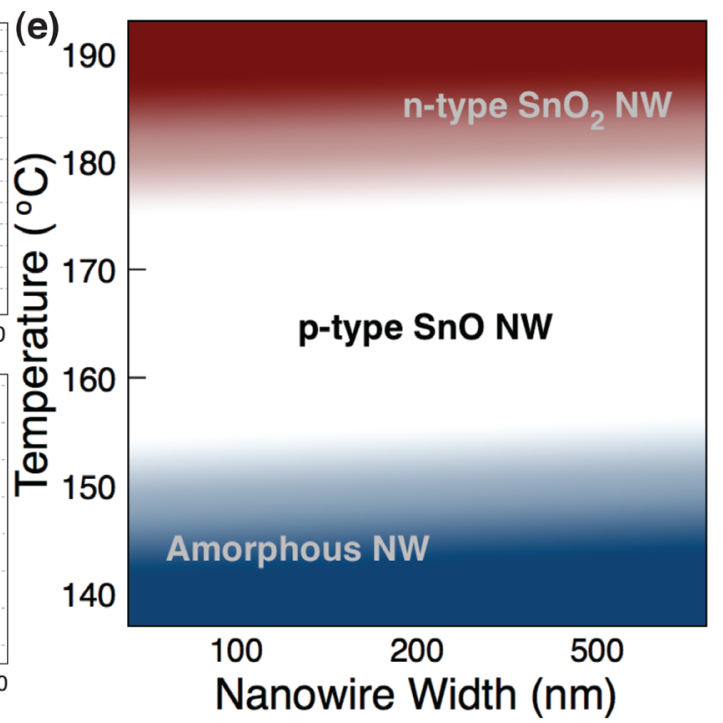

FIG. 3. Important NW-FET parameters measured as a function of nanowire width and anneal temperature: (a) field-effect mobility ( $\left.\mu_{F E}\right)$; (b) threshold voltage $\left(V_{T}\right)$; (c) subthreshold swing $(S S)$; (d) effective hysteresis density $\left(N_{H Y S}\right)$. All devices shown here were fabricated using HfO 2 gate dielectric. (e) Process map depicting process conditions where p-type conduction is observed in SnO NW FETs.

temperature for devices fabricated using $\mathrm{HfO}_{2}$ as gate dielectric. Output and transfer characteristics are shown in Figure $\mathrm{S} 4$ of the supplementary material. ${ }^{35}$ At $150^{\circ} \mathrm{C} \mathrm{SnO}$ is not completely crystallized (as shown in TEM, Fig. S5 (Ref. 35)), so the devices show a rather modest $\mu_{F E}$ (Fig. 3(a)), positive $V_{T}$ (Fig. 3(b)), large $S S$ (Fig. 3(c)), and high $N_{H Y S}$ (Fig. 3(d)). The last two parameters reflect a high density of trap states in the $\mathrm{SnO}$ channel $(S S)$ and the $\mathrm{SnO} / \mathrm{HfO}_{2}$ interface $\left(N_{H Y S}\right)$, which significantly reduces as the annealing temperature increases. At $160^{\circ} \mathrm{C}$ and $170^{\circ} \mathrm{C}$, SS reduces from around $11 \mathrm{Vdec}^{-1}$ at $150^{\circ} \mathrm{C}$ to an average of 0.74 $\mathrm{Vdec}^{-1}$ (Fig. 3(c)), showing that once the active layer is completely crystallized the $\mathrm{SnO} / \mathrm{HfO}_{2}$ interface is of relatively high quality. This statement is confirmed in Fig. 3(d), where the $N_{H Y S}$ is nearly the same for all devices annealed at $160^{\circ} \mathrm{C}$ and $170^{\circ} \mathrm{C}$. Nevertheless, the mobility and threshold voltage degrades at temperatures higher than $160^{\circ} \mathrm{C}$, as observed for devices annealed at $170^{\circ} \mathrm{C}$. The devices convert to weak n-type conduction when annealed at $180^{\circ} \mathrm{C}$ (not shown) and mainly attributed to the oxygen disproportionation mechanism ${ }^{37}$ in which the incorporation of excess oxygen into $\mathrm{SnO}$ causes a transformation to an oxygen-deficient $\mathrm{SnO}_{2}$ phase. In summary, at $150^{\circ} \mathrm{C}$ the $\mathrm{SnO}$ NWs are not completely crystallized, at $160^{\circ} \mathrm{C}$ they show the best p-type performance, at $170^{\circ} \mathrm{C}$ they are affected by additional oxygen incorporation, and at $180^{\circ} \mathrm{C}$ they exhibit weak n-type conduction as summarized in Figure 3(e).

Figure 4 compares the important FET parameters for devices fabricated at the best performance condition when using $\mathrm{HfO}_{2}$ and ATO as gate dielectric. $\mu_{F E}$ on ATO is around half of the $\mu_{F E}$ on $\mathrm{HfO}_{2}$ while there is no clear trend on $V_{T}$ as shown in Fig. 4(a). The $\mathrm{I}_{\mathrm{ON}} / \mathrm{I}_{\mathrm{OFF}}$ ratio is in general one order of magnitude higher on $\mathrm{HfO}_{2}\left(10^{3}\right)$ as shown in Fig. 4(b). The gate leakage current of ATO is as high as $3 \times 10^{-9}$ A, which significantly affects the device off current, thus reducing the $\mathrm{I}_{\mathrm{ON}} / \mathrm{I}_{\mathrm{OFF}}$ ratio. Figure $4(\mathrm{c})$ shows the huge difference in the $S S$ for both dielectrics, indicating a much better interface formation between the $\mathrm{SnO}$ and $\mathrm{HfO}_{2}$, which is also confirmed by the lower $N_{H Y S}$ (Fig. 4(d)) extracted from devices fabricated on $\mathrm{HfO}_{2}$. Despite the fact that these two high-k oxides have comparable dielectric constant ( $\sim 14$ for $\mathrm{HfO}_{2}$ and $\sim 15$ for ATO, and similar $\mathrm{C}_{\text {ox }}$ was used), the low $V_{T}, S S$, and $N_{H Y S}$ of devices fabricated on $\mathrm{HfO}_{2}$ compared to the higher variability of $V_{T}$ as a function of NW width, higher $S S, N_{H Y S}$, and gate leakage current of devices on ATO shows that $\mathrm{SnO} / \mathrm{HfO}_{2}$ interface is more suitable for maximizing device performance. The relatively poorer performance on ATO seems to arise from the higher (a)

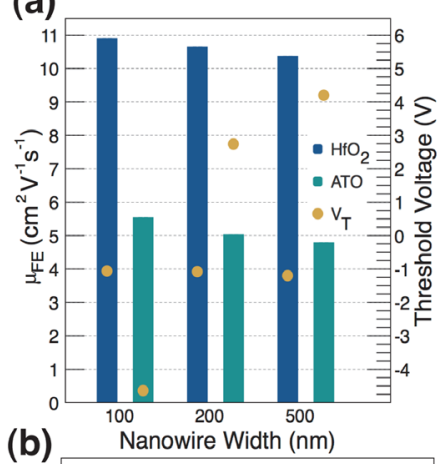

(b)

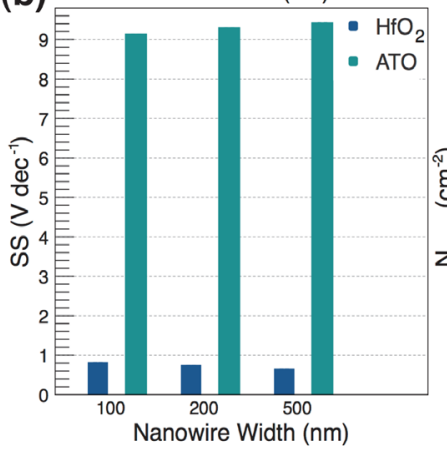

(c)

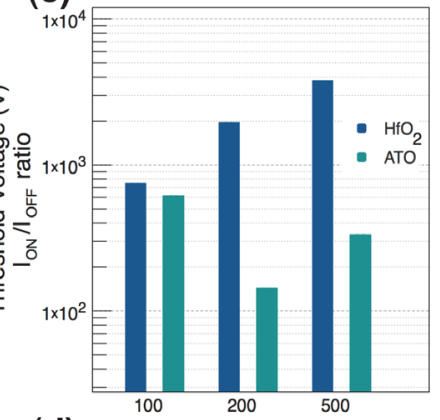

(d)

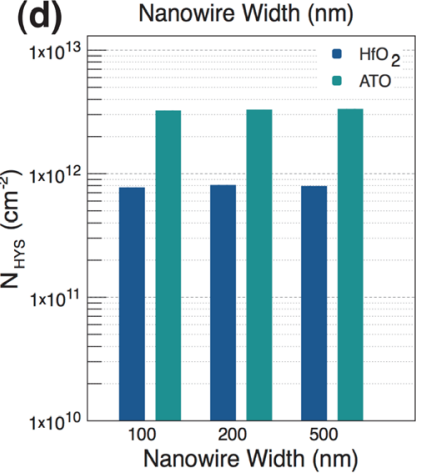

FIG. 4. Effect of gate dielectric material on the performance of NW-FETs fabricated at the optimum anneal temperature $\left(160^{\circ} \mathrm{C}\right)$. (a) Field-effect mobility $\left(\mu_{F E}\right)$ and threshold voltage $\left(V_{T}\right)$; (b) subthreshold swing $(S S)$; (c) onto-off current ratio $\left(\mathrm{I}_{\mathrm{ON}} / \mathrm{I}_{\mathrm{OFF}}\right)$; (d) effective hysteresis density $\left(N_{H Y S}\right)$. 
density of trap states at the $\mathrm{SnO} / \mathrm{ATO}$ interface as well as from the degradation of ATO during the fabrication process caused mainly by e-beam exposure during the active patterning.

We have demonstrated the fabrication of transparent p-type SnO NW-FETs with unprecedented performance at low process temperatures $\left(160^{\circ} \mathrm{C}\right)$. The SnO NW-FETs exhibit the highest reported field-effect hole mobility $\left(10.83 \mathrm{~cm}^{2} \mathrm{~V}^{-1} \mathrm{~s}^{-1}\right)$ of any p-type oxide semiconductor processed at such low temperature. Compared to thin film transistors (TFTs) using the same SnO film, the NW-FETs exhibit five times higher mobility and one order magnitude lower subthreshold slope. In addition, the $\mathrm{SnO}$ nanowire FETs show exceptionally low threshold voltages $(\sim-1 \mathrm{~V})$, which is nearly three times smaller than the thin film device. We have also shown that the use of $\mathrm{HfO}_{2}$ as gate dielectric increases $\mathrm{SnO}$ nanowire device mobility due to a better dielectric/semiconductor interface with reduced trap states.

J. A. Caraveo-Frescas thanks Weisheng Yue and Basil Chew from KAUST nanofabrication facility for their support on e-beam lithography and Qingxiao Wang for TEM imagining.

${ }^{1}$ O. Madelung, Technology and Applications of Amorphous Silicon (Springer, Berlin, 2000).

${ }^{2}$ S. Ucjikoga, MRS Bull. 27, 881 (2002).

${ }^{3}$ D. E. Mentley, Proc. IEEE 90, 453 (2002).

${ }^{4}$ T. P. Brody, IEEE Trans. Electron Devices 31, 1614 (1984).

${ }^{5}$ S. Ju, A. Facchetti, Y. Xuan, J. Liu, F. Ishikawa, P. Ye, C. Zhou, T. J. Marks, and D. B. Janes, Nat. Nanotechnol. 2(6), 378 (2007).

${ }^{6}$ R. H. Reuss, B. R. Chalamala, A. Moussessian, M. G. Kane, A. Kumar, D. C. Zhang, J. A. Rogers, M. Hatalis, D. Temple, G. Moddel, B. J. Eliasson, M. J. Estes, J. Kunze, E. S. Handy, E. S. Harmon, D. B. Salzman, J. M. Woodall, M. A. Alam, J. Y. Murthy, S. C. Jacobsen, M. Olivier, D. Markus, P. M. Campbell, and E. Snow, Proc. IEEE 93(7), 1239 (2005).

${ }^{7}$ E. Fortunato, P. Barquinha, and R. Martins, Adv. Mater. 24(22), 2945 (2012).

${ }^{8}$ K. Nomura, H. Ohta, A. Takagi, T. Kamiya, M. Hirano, and H. Hosono, Nature 432(7016), 488 (2004).

${ }^{9}$ H. Huang, B. Liang, Z. Liu, X. Wang, D. Chen, and G. Shen, J. Mater. Chem. 22(27), 13428 (2012).

${ }^{10}$ D. S. Ginley, H. Hosono, and D. C. Paine, Handbook of Transparent Conductors (Springer, New York, 2010).

${ }^{11}$ B. Kim, C. H. Nyuck, C. W. Seok, K. Seung-Hee, J. Y. Ho, Y. Juhn-Suk, Y. S. Young, J. Myungchul, H. Yong-Kee, and H. Min-Koo, IEEE Electron Device Lett. 33(4), 528 (2012).

${ }^{12}$ K. M. Kim, C. W. Kim, J.-S. Heo, H. Na, J. E. Lee, C. B. Park, J.-U. Bae, C.-D. Kim, M. Jun, Y. K. Hwang, S. T. Meyers, A. Grenville, and D. A. Keszler, Appl. Phys. Lett. 99(24), 242109 (2011).
${ }^{13}$ S. N. Cha, J. E. Jang, Y. Choi, G. A. J. Amaratunga, G. W. Ho, M. E. Welland, D. G. Hasko, D. J. Kang, and J. M. Kim, Appl. Phys. Lett. 89(26), 263102 (2006).

${ }^{14}$ P.-C. Chen, G. Shen, H. Chen, Y.-G. Ha, C. Wu, S. Sukcharoenchoke, Y. Fu, J. Liu, A. Facchetti, T. J. Marks, M. E. Thompson, and C. Zhou, ACS Nano 3, 3383 (2009).

${ }^{15}$ G. Shen, J. Xu, X. Wang, H. Huang, and D. Chen, Adv. Mater. 23(6), 771 (2011).

${ }^{16}$ D. Chen, Z. Liu, B. Liang, X. Wang, and G. Shen, Nanoscale 4, 3001 (2012).

${ }^{17}$ K. Trivedi, H. Yuk, H. C. Floresca, M. J. Kim, and W. Hu, Nano Lett. 11(4), 1412 (2011).

${ }^{18}$ Z. Q. Yao, S. L. Liu, L. Zhang, B. He, A. Kumar, X. Jiang, W. J. Zhang, and G. Shao, Appl. Phys. Lett. 101(4), 042114 (2012).

${ }^{19}$ X. Zou, F. Guojia, Y. Longyan, L. Meiya, G. Wenjie, and Z. Xingzhong, Electron Devices Lett. 31(8), 827 (2010).

${ }^{20}$ K. Matsuzaki, K. Nomura, H. Yanagi, T. Kamiya, M. Hirano, and H. Hosono, Appl. Phys. Lett. 93(20), 202107 (2008).

${ }^{21}$ E. Fortunato, V. Figueiredo, P. Barquinha, E. Elamurugu, R. Barros, G. Goncalves, S.-H. K. Park, C.-S. Hwang, and R. Martins, Appl. Phys. Lett. 96(19), 192102 (2010).

${ }^{22}$ E. Fortunato, R. Barros, P. Barquinha, V. Figueiredo, S.-H. K. Park, C.-S. Hwang, and R. Martins, Appl. Phys. Lett. 97(5), 052105 (2010).

${ }^{23}$ H.-N. Lee, H.-J. Kim, and C.-K. Kim, Jpn. J. Appl. Phys. 49(2), 020202 (2010).

${ }^{24}$ L. Y. Liang, Z. M. Liu, H. T. Cao, W. Y. Xu, X. L. Sun, H. Luo, and K. Cang, J. Phys. D: Appl. Phys. 45(8), 085101 (2012).

${ }^{25}$ Y. Ogo, H. Hiramatsu, K. Nomura, H. Yanagi, T. Kamiya, M. Hirano, and H. Hosono, Appl. Phys. Lett. 93(3), 032113 (2008).

${ }^{26}$ H. Yabuta, N. Kaji, R. Hayashi, H. Kumomi, K. Nomura, T. Kamiya, M. Hirano, and H. Hosono, Appl. Phys. Lett. 97(7), 072111 (2010).

${ }^{27}$ A. Togo, F. Oba, I. Tanaka, and K. Tatsumi, Phys. Rev. B 74(19), 195128 (2006).

${ }^{28}$ Y. Ogo, H. Hiramatsu, K. Nomura, H. Yanagi, T. Kamiya, M. Kimura, M. Hirano, and H. Hosono, Phys. Status Solidi A 206(9), 2187 (2009).

${ }^{29}$ J. A. Caraveo-Frescas, P. K. Nayak, H. A. Al-Jawhari, D. B. Granato, U. Schwingenschlögl, and H. N. Alshareef, ACS Nano 7, 5160 (2013).

${ }^{30}$ L. Liao, Z. Zhang, B. Yan, Z. Zheng, Q. L. Bao, T. Wu, C. M. Li, Z. X. Shen, J. X. Zhang, H. Gong, J. C. Li, and T. Yu, Nanotechnology 20(8), 085203 (2009).

${ }^{31}$ L. Liao, B. Yan, Y. F. Hao, G. Z. Xing, J. P. Liu, B. C. Zhao, Z. X. Shen, T. Wu, L. Wang, J. T. L. Thong, C. M. Li, W. Huang, and T. Yu, Appl. Phys. Lett. 94(11), 113106 (2009).

${ }^{32}$ B. Kumar, D.-H. Lee, S.-H. Kim, B. Yang, S. Maeng, and S.-W. Kim, J. Phys. Chem. C 114, 11050 (2010).

${ }^{33}$ M. O. Orlandi, E. R. Leite, R. Aguiar, J. Bettini, and E. Longo, J. Phys. Chem. B 110, 6621 (2006).

${ }^{34}$ M. Z. Iqbal, F. Wang, D. Rafi ud, Q.-U.-A. Javed, M. Y. Rafique, Y. Li, and P. Li, Mater. Lett. 68, 409 (2012).

${ }^{35}$ See supplementary material at http://dx.doi.org/10.1063/1.4833541 for experimental details, transmission spectra of $\mathrm{SnO}$, and additional transfer curves of NW-FET and TFT devices.

${ }^{36}$ J. F. Wager, J. Soc. Inf. Disp. 18(10), 749 (2010).

${ }^{37}$ J. Geurts, S. Rau, W. Richter, and F. J. Schmitte, Thin Solid Films 121(3), 217 (1984). 